\title{
A TRAJETÓRIA DO AVAÍ FUTEBOL CLUBE NO CAMPEONATO BRASILEIRO 2009: LEITURA DE CHARGES JORNALÍSTICAS
}

\author{
DR. FÁBIO DE CARVALHO MESSA \\ Doutorado em Literatura e Mestrado em Educação Física, ambos pela Universidade Federal de Santa \\ Catarina (UFSC), Professor Adjunto da Universidade Federal do Paraná/Setor Litoral, Laboratório e \\ Observatório da Mídia Esportiva (LaboMidia/UFSC) \\ (Matinhos - Paraná - Brasil) \\ E-mail: fabiomessa@ufpr.br
}

\section{DR. GIOVANI DE LORENZI PIRES}

Doutorado em Educação Física pela Universidade Estadual de Campinas (UNICAMP)

Professor Associado do Departamento de Educação Física da Universidade Federal de Santa Catarina, Laboratório e Observatório da Mídia Esportiva (LaboMidia/UFSC)

(Florianópolis - Santa Catarina - Brasil)

E-mail: giovani.pires@ufsc.br

\section{RESUMO}

Este trabalho oferece aos professores de Educação Física um respaldo teórico-crítico sobre análise semiótico-discursiva de charges jornalísticas de futebol nos veículos impressos da Grande Florianópolis. Trata-se de uma leitura do desempenho do Avaí F. C. no Campeonato Brasileiro de 2009, a partir das charges produzidas de maio a dezembro daquele ano por Zé Dassilva (Diário Catarinense), Mendes (Notícias do Dia) e Adorno (Hora de Santa Catarina). 0 percurso analítico leva em conta uma escolha peculiar de charges, dispostas cronologicamente, que se destacam por evidenciar alguns fenômenos e elementos constituintes dos processos semiósicos e discursivos das narrativas da performance do Leão, ao longo do campeonato, como metaforização e metonimização.

PALAVRAS-CHAVE: Análise semiótico-discursiva; charges jornalísticas; campeonato brasileiro de futebol; Avaí Futebol Clube. 
O ano de 2009 foi bastante significativo para o Avaí Futebol Clube, o Leão da Ilha.' Primeiro porque a equipe rompeu um jejum de cerca de 19 anos em termos de grandes vitórias e títulos e, essencialmente, garantiu seu retorno ao campeonato da primeira divisão do futebol brasileiro (série A). Segundo, porque trocou de lugar com o seu maior rival, o Figueirense, que no mesmo ano foi rebaixado para a série $B$.

A partir daí, estruturou-se um contexto propício para a narrativização jornalística local dessa antinomia: Avaí na série A e Figueirense na série B. Previsivelmente fomentaram-se pautas e mobilizou-se a produção jornalística em torno dos êxitos e fracassos de ambos os times, com maior ênfase para o time da ilha, que esteve sob os focos das lentes e sob os olhares aguçados dos críticos.

Em busca da interpretação desses efeitos de sentido na produção jornalística local, aventurou-se em uma análise semiótico-discursiva dos conteúdos divulgados sobre a trajetória do Avaí Futebol Clube na série A do campeonato brasileiro de $2009,{ }^{2}$ a partir das charges publicadas nos três jornais de maior circulação na região de Florianópolis. Foram levadas em conta as ilustrações de Zé Dassilva (Diário Catarinense - DC), Adorno (Hora de Santa Catarina - HSC) e Mendes (Notícias do Dia - ND) ${ }^{3}$ para desenvolver o percurso analítico. Assim, foi possível acompanhar o desempenho do time no desenrolar da competição, a partir da visão dos chargistas em suas ilustrações divulgadas nos periódicos.

Este estudo vem se somar a outras investigações do campo de interlocução entre esporte e mídia, notadamente aqueles que se destinam a realizar análises críticas de produtos da mídia esportiva (ALVES; SANTOS, 20 I 0; BITENCOURT et al., 2009; MESSA, 2009; MEZZAROBA; PIRES, 20 I 0; PIRES et al., 2009, FREITAS; RIGO, 2009; SANFELICE, 20 I0), objetivando compreender o papel da mídia na construção de representações socialmente compartilhadas a respeito do esporte.

O pressuposto da pesquisa é que as charges jornalísticas integram o discurso midiático, constituindo-se numa narrativa específica do fenômeno esportivo, que associa diferentes elementos discursivos e simbólicos. Assim, além de contribuir para

I. O Avaí tem sua sede na parte insular da cidade de Florianópolis/SC, na llha de Santa Catarina; já o seu rival local, o Figueirense, localiza-se na parte continental da cidade, no bairro Estreito.

2. A pesquisa constituiu-se em dissertação de mestrado apresentada ao PPGEF/UFSC (MESSA, 20 I 0 ). trabalho não teve apoio financeiro para sua realização. Não houve conflitos de interesses na realização do estudo.

3. Os jornais Hora de Santa Catarina e Diário Catarinense pertencem à RBS, grupo empresarial de comunicação com sede em Porto Alegre/RS. O Notícias do Dia integra a empresa catarinense de mídia RIC/Record. 
a compreensão dessa forma de abordagem do esporte no meio jornalístico, o estudo também visa a proporcionar aos professores de Educação Física um referencial teórico-metodológico para o trato analítico e pedagógico do esporte midiatizado, neste caso, por meio das charges.

\section{NO UNIVERSO DAS CHARGES}

Efetuando-se consulta em bases bibliográficas brasileiras, verificamos pouca diversidade de referências que tratem teoricamente de charges nos últimos I 0 anos. Não há propriamente uma teoria do texto-charge ou do fazer chargístico; o que existe são algumas definições do gênero, assim como suas distinções de caricatura e cartum em dicionários de comunicação, livros de introdução ao jornalismo, manuais de redação e estilo jornalísticos e em textos teóricos sobre jornalismo opinativo.

Nestes últimos, vale referir Melo (2003) e Erbolato ( 198 I), em cujas obras a caracterização da charge surge como uma peculiaridade dos textos de opinião, destacando sua importância enquanto ilustração no âmbito do editorialismo jornalístico. Amaral (1982) também menciona a charge como subtipo do gênero jornalístico opinativo.

Estabelecendo distinções, Rabaça e Barbosa (1978, p. 89), no antológico Dicionário de Comunicação, determinam a caricatura como "uma forma de arte que se expressa através do desenho, da pintura, da escultura, etc., cuja finalidade é o humor". Seriam subdivisões da caricatura: a charge, o cartum e o desenho humorístico. $\bigcirc$ cartum é referido como uma anedota gráfica, que provoca o riso do leitor. Consiste numa das manifestações caricaturais que leva o leitor ao riso por meio de uma crítica mordaz, irônica, satírica e humorística do comportamento humano, assim como de suas fraquezas, hábitos e costumes.

A charge seria, portanto, um tipo de cartum "cujo objetivo é a crítica humorística de um fato ou acontecimento específico, em geral de natureza política" (RABAÇA; BARBOSA, 1978, p. 89). De acordo com esses autores, a boa charge deve procurar um assunto atual e centrado na atenção e no interesse do público leitor.

Charge consistiria, assim, num desenho humorístico, que pode ter legendas ou não, geralmente veiculado no jornalismo impresso, que tem por tema algum acontecimento factual, comportando crítica e focalizando, por meio de versões caricaturais de sujeitos/personagens, fatos da atualidade. Pode ser entendida também como composição sígnica, representação pictórica, de caráter burlesco e caricatural, com que se satiriza uma ideia, situação ou pessoa. Nos dicionários é possível encontrar os termos caricatura e cartum como sinônimos.

Quanto às consultas realizadas em bases eletrônicas, no âmbito das produções acadêmicas em nível de pós-graduação, preponderam trabalhos pertinentes 
ao campo das ciências da comunicação e da linguagem. Tem-se, por exemplo, o trabalho de Almeida e Oliveira (2006), que atestam a diferença conceitual entre os gêneros jornalísticos opinativos de humor na imprensa: caricaturas e charges. Para as autoras, há uma dificuldade em diferenciar os gêneros jornalísticos, e elas ressaltam a importância da leitura e da interpretação, relacionando o texto com o contexto para uma interpretação eficaz.

Magalhães (2006), pautado nos pressupostos da teoria de Michel Pêcheux (análise do discurso de base francesa), vislumbra o processo de produção de sentidos das charges a partir da relação entre as suas condições imediatas de produção (historicidade) e o interdiscurso (memória discursiva). Ainda com base em Pêcheux e outros autores da AD francesa, o trabalho de Baronas e Aguiar (2009) mostra que as charges impressas mantêm, com os acontecimentos históricos, não apenas uma relação argumentativa ou dialógica, mas uma relação de interdiscursividade cultural. Ainda sobre interdiscursividade, convém referir o trabalho de Moura (2010) que, numa mesma abordagem, analisou algumas charges políticas e esportivas sobre as Olimpíadas em Pequim/2008.

Com base nas teorias literárias de Vladimir Propp (1992), Nogueira (2003) analisa personagens-tipos como Juca Pato e Zé Marmiteiro, das charges paulistanas. Outros estudos direcionam-se à discussão sobre a charge enquanto gênero textual, um dos temas mais relevantes e recentes nas pesquisas linguísticas e literárias no Brasil. Os teóricos de base sobre gêneros textuais são os russos Mikhail Bakhtin e Tzvedan Todorov.

gênero textual não designa apenas um tipo particular de texto, materializado tecnicamente de uma forma, mas também as suas condições particulares de produção, distribuição e também de consumo. Assim, considerando a charge não só como gênero jornalístico, mas antes disso um gênero textual, parece viável constatar e discutir, como já fizeram diversos pesquisadores, que o texto da charge ocorre num determinado contexto (veículo impresso, para uma determinada comunidade jornalística), envolvendo distintos agentes (relações texto-leitor), que produzem e consomem, leem e interpretam.

Trevisan (1992) também ressaltou que a charge tem grande valor como texto, pois se define pelo uso de linguagem híbrida (verbal e não-verbal):

As formas de percepção da charge se materializam por meio da escrita e do desenho, sendo a síntese olho-ouvido resultante o vestígio que testemunha e registra a concorrência de signos sociolingüísticos, culturais, ideológicos, psicológicos presentes a um só tempo nesse tipo de produto cultural. O componente lingüístico é co-responsável, juntamente com os componentes gráfico e imagético, pelo grau de informatividade e poder argumentativo, persuasivo da mensagem. (TREVISAN, 1992, p. 34). 
todo da charge consiste numa mistura de diversos elementos que contribuem para formar um todo ainda maior de sentidos, intenções e crenças, permitindo ao leitor captar a trama do encontro entre o pensamento popular e os vários dizeres, falares e pensares que existem na sociedade. Trevisan (1992) complementa, classificando a charge como um tipo de texto sui-generis, que mostra e conta, simultaneamente, os conflitos sociais.

A charge contém um posicionamento crítico e de confronto de opiniões a respeito da organização social, dos arranjos políticos e da disputa de poder. Sua temática, em geral, retrata o cotidiano: questões sociais que afligem, irritam, desgostam, divertem, e às vezes até confundem. [...]. A intervenção da charge no mundo cultural inicia-se pelo reconhecimento de significados já existentes e pelo estabelecimento de relações que atribuem um sentido determinado à mensagem. (TREVISAN, 1992, p. 39-40)

A charge, como texto de massa para consumo imediato, também se institui em uma rede de saberes já compartilhada entre autores e leitores. A interação da charge com o leitor ocorre por meio de um processo que é imposto à recepção, a partir de determinadas informações já conhecidas de ambos os lados.

Para ilustrar esse fenômeno, nada mais conveniente do que pensar em charges esportivas que, ao referirem-se aos times mais diversos, recuperam um arsenal de elementos que já fazem parte do cotidiano e do repertório cultural de seus leitores-torcedores, que são as imagens das mascotes e símbolos dos clubes, caricaturizados (parafraseados ou parodiados).

Então, já se sabe que o Leão representado numa charge específica se refere ao Avaí; o Saci, ao Internacional; o Porco, ao Palmeiras; e assim por diante. Por isso, a carga ideológica da charge é fortíssima, pois o seu mostrar e o seu dizer já têm lugar social definido, que pressupõe um conhecimento prévio considerável, exigindo do leitor um repertório básico, para ativar seu conhecimento armazenado, chegando, por fim, à chamada compreensão.

A prova cabal de que o conhecimento de mundo está diretamente ligado à compreensão das charges esportivas, é o fato de muitos leitores leigos, como uma dona de casa que não acompanha futebol, por exemplo, não conseguirem apreender o sentido, porque desconhecem o repertório mínimo sobre a biunivocidade entre o clube/time e sua representação simbólica através de uma mascote específica.

Há ainda outros estudos sobre charges que a concebem numa perspectiva discursiva, propondo discussões a partir de conceitos da linguística textual e da linguística da enunciação, como o de textualidade e intertextualidade. A charge é considerada uma forma de comunicação condensada de informações, cujo entendimento depende do mesmo conjunto de dados (partilhados por leitor e autor, como 
dito anteriormente), e fatos contemporâneos ao momento específico em que se estabelece a relação discursiva entre o produtor e o receptor.

Beaugrand e Dressler (apud KOCH, 2000) afirmam que são sete os fatores responsáveis pela textualidade: coerência, coesão, intencionalidade, aceitabilidade, informatividade, situacionalidade e intertextualidade. Os dois primeiros fatores (coerência e coesão) estão centrados na micro e macro-estrutura do texto. Os demais fatores estão concentrados no leitor.

Embora todos esses fatores possam ser identificados e discutidos em textos não verbais, como a charge, o que mais se evidencia, em termos de reflexões teóricas de cunho acadêmico, é a intertextualidade, já que se refere aos aspectos que tornam a utilização de um texto (produção e recepção) dependente de outro(s) texto(s) previamente existente(s).

Sendo a intertextualidade um dos critérios de textualidade, ela

Compreende as diversas maneiras pelas quais à produção e recepção de dado texto depende do conhecimento de outros textos por parte dos interlocutores, isto é, diz respeito aos fatores que tornam a utilização de um texto dependente de um ou mais textos previamente existentes, pois existe um diálogo entre textos ( $\mathrm{KOCH}, 2000$, p. I I 2).

Então a charge, que é de natureza gráfica, também apresenta alguns destes critérios firmados para textos verbais, dentre eles, a interdiscursividade, por estabelecer relações entre o texto-base e outros textos produzidos.

Isso gera a constatação, portanto, de que todo texto é um intertexto, pois outros textos sempre estarão presentes nele, em diversos níveis. E o discurso da charge fica assim estabelecido como uma trama que se dirige a determinados sujeitos socialmente situados, já inscritos em uma dada ideologia, pois só na medida em que o são é que se tornam receptores capazes de decodificar as referências ativadas e cooperar na sua construção de sentido.

Mesmo que as charges esportivas de futebol sejam destinadas a um tipo de leitor, que é torcedor e já tem internalizado um repertório mínimo capaz de levá-lo à interpretação pretendida pelo emissor, a sua leitura será sempre diferente para cada um, já que cada sujeito cria um contexto, constituindo-o e interpretando-o, à medida que o conhecimento vai se articulando ao que está arquivado no plano da memória.

Um dos poucos trabalhos aqui rastreados, que tangenciam o texto jornalístico esportivo, é o de Camargo (2000), que tenta compreender as tendências utilizadas na chamada das matérias esportivas dos jornais Correio Popular e Folha de São Paulo, em relação à cobertura da Copa do Mundo de 98, na França. Apenas refere-se a charges, quando procura identificar os gêneros jornalísticos priorizados. 
Isso posto, pode-se considerar que o olhar semiótico que se debruça neste estudo sobre as charges esportivas é, até então, inédito, no campo das Ciências do Esporte no Brasil. Vale destacar que no campo da Linguística e da Comunicação, a maior parte da fortuna crítica encontrada sobre charges não se refere ao tema esporte, mas sim à economia e à política.

$\bigcirc$ que se quer aqui precisamente enfatizar é que, na abordagem jornalística popular do futebol, personalizam-se equipes, jogadores e/ou técnicos, condensando-os em figuras simbólicas, míticas, e que a narratividade e o debate sobre futebol provocam sensações no público porque surgem aos seus olhos como um produto espetacular, com todas as alegorias que lhes são pertinentes.

Então, entre colunas sociais, receitas culinárias, guias astrológicos, casos policiais, anúncios promocionais, relatos de eventos e matérias de esportes, as charges surgem como elemento adicional e imprescindível dentro deste mosaico, para conduzir o público leitor a um posicionamento crítico ou para uma fruição, senão estética, pelo menos, de lazer. Esse campo dinâmico entre a produção e a recepção é o ponto-chave para entender como as charges são compreendidas, pois é preciso especular não só sobre as condições de produção das mensagens, como também sobre suas possibilidades receptivas.

Como dissemos, para este estudo selecionamos as charges de Zé Dassilva, Adorno e Mendes referentes ao desempenho e peripécias do Leão da Ilha, símbolo do Avaí F.C., para mostrar como se constrói o efeito de humor e o percurso gerativo do sentido, que traz de forma subjacente à crítica deste gênero jornalístico. Abrimos, portanto, a porteira, para conhecer um pouco do universo sígnico (mítico e zoossemiótico) das narrativas chargísticas sobre o Avaí, no Brasileirão/2009.4

\section{TEMPORALIDADE}

Um critério bastante providencial para que se possa contemplar as charges em suas sucessões, conforme o andamento das rodadas e turnos, é o da temporalidade. A partir desse eixo, já se pensa em duas marcas fortes: a do pré-jogo e a do pós-jogo.

Há chargistas como Adorno (HSC) que, pelo fato de estar na condição de ilustrador do veículo, costumam preparar o leitor para o jogo do dia, criando uma espécie de prognóstico, agendamento, geralmente positivo, da rodada, assim como caracterizar, no outro dia, como foi o seu desfecho. Frequentemente, a vitória propicia publicação garantida da charge pós-jogo, embora, dependendo do desempenho

4. No estudo original, foram analisadas 77 charges dos três artistas; para este artigo, foram selecionadas apenas algumas destas, apresentadas para ilustrar os eixos de discussão que compõem o presente texto. 
da equipe, uma derrota vergonhosa possa, também, não só tematizar a charge pós-jogo, como até rechear matérias de capa da edição do jornal.

Dentre os três chargistas escolhidos, foi Adorno (HSC) quem mais cumpriu agenda pré e pós-jogo. Zé Dassilva (DC), algumas vezes; e Mendes (ND), raramente. As ocorrências que menos favorecem a produção de charges são as das rodadas que resultam em empate.

Foi na $4^{a}$ rodada que surgiram as charges pré e pós-jogo de Adorno, mostrando pela primeira vez o Saci (mascote do Internacional/POA) interagindo em peripécias com o Leão. Na primeira, pré-jogo, Adorno recupera os caracteres próprios da narrativa mítica do Saci, colocando-o submetido às garras do Leão, dentro do pequeno frasco de vidro. Dizia-se que era privilégio de poucos manter o Saci minúscula e magicamente reduzido dentro de uma garrafa ou dispositivo similar. A pré-charge antecipa positivamente a partida, pressupondo a supremacia do Leão diante do Saci, numa relação de poder - animal simbólico x figura mítica abstrata, a ferocidade de um felino contra a subjetividade de um ser mitológico.

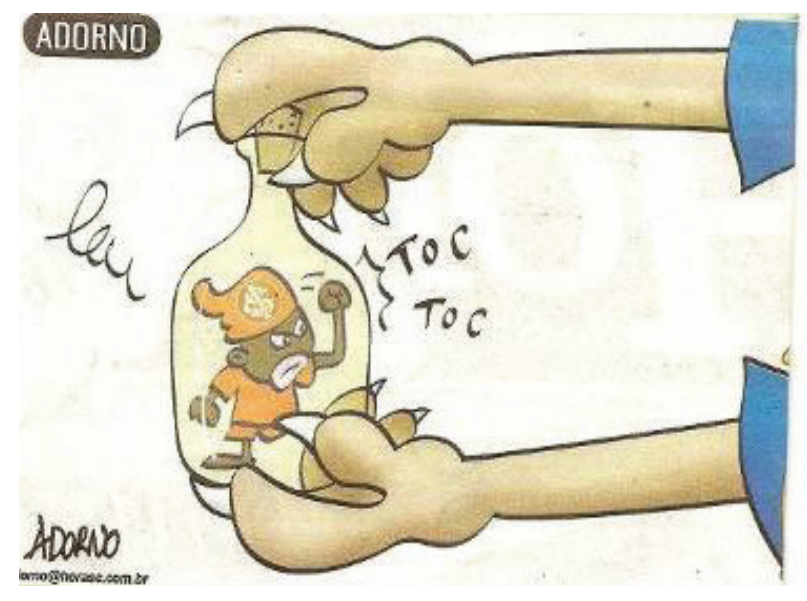

Figura I. Charge de Adorno.

Fonte: Jornal: "Hora de Santa Catarina" (HSC), 30 maio 2009.

Mas a charge pós-jogo não pode evitar o revés do protagonista. Do mesmo tamanho, já em forma corporificada, surge o Saci de chuteiras, baforando com seu poderoso cachimbo a juba do Leão, que tosse atrapalhadamente diante do placar contrário de 2xI. Geralmente, as charges de pós-jogo que mostram a derrota do 
Leão vêm mais carregadas de componentes retóricos, em forma de figuras como metáfora e hipérbole, explicitando a crítica ideológica.

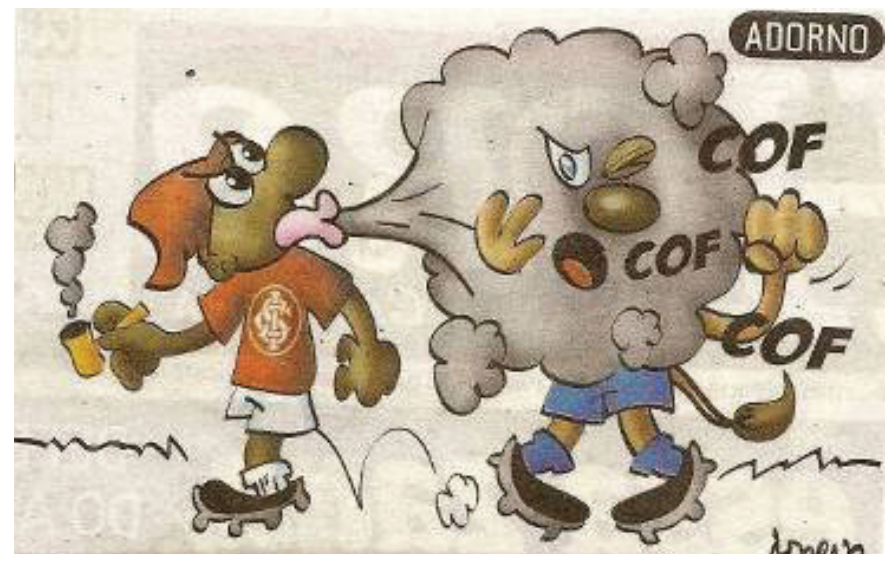

Figura 2. Charge de Adorno.

Fonte: Jornal: "Hora de Santa Catarina" (HSC), O I jun. 2009.

O processo metafórico se institui quando o sujeito, para designar um objeto, não o faz objetivamente, chamando-o pelo nome próprio ou comum, mas recorre a outro campo semântico (campo de significação) para eleger um outro elemento que, em princípio, estaria totalmente fora do conjunto das qualidades essenciais que poderiam ser atribuídas àquele objeto.

Por exemplo, quando se chama, pejorativamente, um sujeito de porco, de cobra ou de cachorro, se quer caracterizá-lo a partir de atributos que esses animais possuem. Portanto, se constrói a metáfora, que consiste numa comparação entre dois elementos, a partir de duas características que possam ter em comum, conotativamente.

Câmara Jr. (1986, p. 74) pode ajudar nessa definição de metáfora:

É a figura de linguagem que consiste na transferência de um termo para um âmbito de significação que não é o seu; não se fundamenta numa relação objetiva entre a significcação própria e a figurada, mas sim, numa relação toda subjetiva, criada no trabalho mental de apreensão.

Já a hipérbole é uma figura de retórica formada a partir da mesma linha de raciocínio da metáfora, consistindo num exagero da significação linguística, para fins 
de expressividade. E não se restringe apenas à expressão verbal, o signo não-verbal também se expande.

A próxima charge, sobre a "lanterna", pode ilustrar bem isso. O termo "lanterna', já desdobrado para formas sígnicas denotativas (com o desenho do objeto, convencionalmente), designa o fenômeno de estar por último na fila, próximo à zona de rebaixamento, sem iluminação, pois o farol é lá adiante, então quem fica com a lanterna já está no escuro.

\section{O FENÔMENO DA LANTERNA}

Dos jogos do Avaí no Brasileiro de 2009, quase um terço dos resultados foi de empate. Nestes casos, muitas vezes o leitor, após sentir-se instigado a assistir ao jogo pela charge do dia, não encontraria charge pós-jogo. E quando havia charge pós-jogo cujo resultado fora o empate, geralmente outra temática era enfatizada, como, por exemplo, a condição de lanterna do campeonato que o Avaí ocupou por algumas rodadas.

A lanterna do Avaí, no traço de Zé Dassilva, confunde-se com a luminosidade do estádio num processo analógico hiberbolizado. A voz do funcionário da torre de comando omite ser aquela luz apenas indicativa da luminosidade do estádio num jogo noturno. $\bigcirc$ chargista não escolhe o contexto do avião e do aeroporto por acaso, arbitrariamente. Aproveita-se de duas unidades culturais - aeroporto Hercílio Luz e estádio da Ressacada - porque estas estão presentes no mesmo sistema significativo que compõe o bairro onde estão situados (Carianos), ou seja, realmente o piloto de um avião, ao pousar no Aeroporto de Florianópolis, enxergará com destaque a luminosidade do estádio.

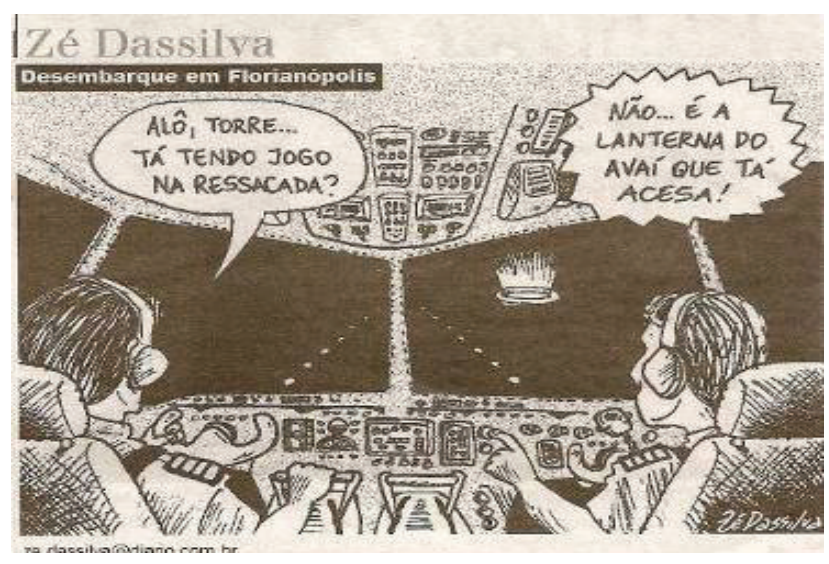

Figura 3. Charge de Zé Dassilva.

Fonte: Jornal: "Diário Catarinense” (DC), 15 jun. 2009. 
O artista oferece não só a similaridade como eixo de raciocínio para o leitor-modelo compreender a mensagem (cooperar textualmente) - ex.: a analogia entre os dois tipos de dispositivos que produzem luz, o estádio iluminado (em grande quantidade) e lanterna (em pequena); mas oferece também a contiguidade como outra linha de raciocínio criativo, quando mapeia para o seu leitor o contexto verossímil de ocorrências das unidades dramáticas em suas charges, para que sejam compreendidas factualmente. A similaridade característica da construção do processo metafórico e icônico; e a contiguidade, própria da construção do processo metonímico e indicial.

É fundamental também estabelecer distinções entre a metáfora e a metonímia, outra importante figura de retórica, cujo processo de criação obedece à lógica da pertinência entre elementos de um mesmo conjunto. Conforme Câmara Jr( 1986, p. 97):

Figura de linguagem que consiste na ampliação do âmbito da significação de uma palavra ou expressão, partindo de uma relação objetiva entre a significação própria e a figurada. A metonímia coloca uma palavra num campo semântico que não é o seu, na base de agrupamentos onomasiológicos das coisas extralingüísticas que não coincidem com os agrupamentos semânticos das formas lingüísticas.

Essas relações objetivas, diferentes das relações subjetivas, próprias do processo metafórico, podem ser de diversas ordens: da parte pelo todo ou todo pela parte - por isso a associação com a pertinência ou continência de elementos dentro de conjuntos (oriundos da matemática), do produto pela matéria, entre autor e obra, continente por conteúdo, etc.

A classificação básica dos signos ocorre a partir da relação que se estabelece na mente do sujeito intérprete entre o signo e o seu objeto. Assim, o signo pode ser dividido em classes, conforme sua própria natureza de formação, quanto a sua relação com seu objeto, e quanto a sua relação com seus interpretantes. Então, o signo em relação a seu objeto pode ser de três tipos: ícone, índice ou símbolo. Segue-se a eles, para depois esclarecer, afinal de contas, o que é o interpretante.

\footnotetext{
Ícones são signos que operam pela semelhança de fato entre suas qualidades, seu objeto e seu significado. Peirce chega a estabelecer os 'hipoícones' ou ícones já materializados que, conforme participam de suas categorias, seriam: as imagens como simples qualidades primeiras; os diagramas que representam relações diádicas e análogas entre suas partes constituintes; e aquelas que tendem à representação, que como as metáforas, traçam algum paralelismo com algo diverso. (PLAZA, 200 I, p. 127)
}

Se antes foi fundamentada a metáfora, então agora resta dizer que o ícone é o tipo de signo que provém da mesma relação comparativa, por similitude. Se a metáfora, a partir do ponto de vista da retórica, pode ocorrer na palavra, na 
expressão verbal; então o ícone, do ponto de vista da semiótica, pode ser vislumbrado na imagem, na representação não-verbal. $\bigcirc$ ícone, portanto, equivale à metáfora, é a metáfora imagética.

Se o ícone equivale à metáfora, devido ao processo de criação, por intersecção de conjuntos; então o índice equivale à metonímia, pois também pode ser representado pelo diagrama de conjunto e subconjuntos. $\bigcirc$ signo será indicial quando apresentar uma informação que instrua, que dê referência, que faça o sujeito-intérprete imediatamente relacionar a outro signo, geralmente, um signo de maior abrangência.

Índices operam antes de tudo pela contigüidade de fato vivida. $O$ índice é um signo determinado pelo seu Objeto Dinâmico em virtude de estar para com ele em relação real. $\bigcirc$ índice, em relação ao seu Objeto Imediato, é um signo de um existente. Fotografias instantâneas são muito instrutivas, porque sabemos que, sob certos aspectos, são exatamente como os objetos que representam. Esta semelhança é devida ao fato de as fotografias serem produzidas em circunstâncias tais que se viram fisicamente compelidas a corresponder, ponto a ponto, à natureza. (PLAZA, 200 I, p. 123).

Desta vez, Adorno é quem coisifica a lanterna, colocando-a no contexto da página de vendas de artigos e produtos do clube, na store virtual do Avaí. Dá destaque ao produto da semana: a lanterna; zomba com a possibilidade do produto ser vendido no site oficial do clube.

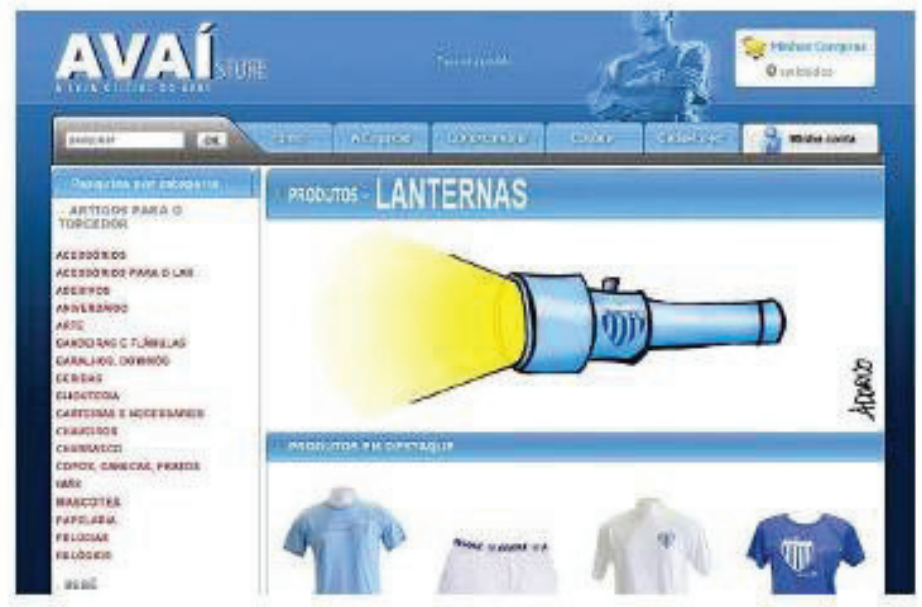

Figura 4. Charge de Adorno.

Fonte: Jornal: "Hora de Santa Catarina" (HSC), I 8 jun. 2009. 
A lanterna se configura originalmente como metonímia, índice, pois provém daquele outro campo semântico (da necessidade da luz, num caminho obscuro), é extraída desse campo e trazida denotativamente, ipsis litteris, para o contexto da charge. Carregar a lanterna ou pôr a lanterna pra vender na própria loja é uma expressão conotativa, que mostra o desdobramento do índice em quase-símbolo, quase-personificação.

Convém reforçar que a denotação é a referência imediata que um termo provoca no destinatário de uma mensagem. Melhor dizendo, denotação poderia ser a referência imediata que o código atribui ao termo numa dada cultura. Neste caso, o termo é 'lanterna', e o código é a forma como ele se apresenta no contexto do futebol.

Já a conotação é o conjunto de todas as unidades culturais que uma definição determinada pode pôr em jogo. É a soma de todas as unidades culturais que um termo pode evocar na mente de um destinatário, não numa possibilidade psíquica, mas numa disponibilidade cultural. Da cultura do senso comum para a cultura futebolística chargeada, a sequência de interpretantes de um termo como a 'lanterna' demonstra que esse termo pode ligar-se a todos os outros signos que de alguma forma a ele foram reportados.

Então, na charge de Adorno, vislumbra-se o investimento figurativo na denotação do termo 'lanterna' para, daí sim, possibilitar a sua expansão conotativa. Ou seja, reforça-se figurativamente o termo 'lanterna', desenhando-a denotativamente, para provocar o efeito inverso na mente do destinatário, que é o de todas as conotações possíveis que o termo possa assumir.

$\mathrm{Na} 10^{a}$ rodada, em pré e pós-jogo, Adorno e Zé Dassilva, colegas de mesma empresa jornalística, revezavam as brincadeiras com a 'lanterna', desta vez no jogo com o Botafogo.

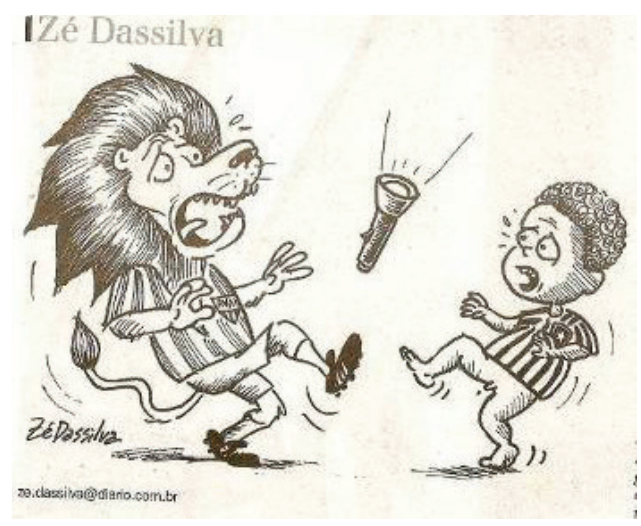

Figura 5. Charge de Zé Dassilva.

Fonte: Jornal: "Diário Catarinense” (DC), I I jul. 2009. 
Zé Dassilva sugere o impasse entre o Leão e o Manequinho, mascote do Botafogo, em torno da 'lanterna'; ou seja, ambas as equipes estão na mesma condição, tentando desvencilhar-se do indesejável objeto.

Adorno também faz a charge pré-jogo, intertextualizando com o filme Star Wars (Guerra nas Estrelas), trilogia de sucesso na década de 80, que já sofreu remaking nos anos 2000. As lanternas de ambos condensaram-se metafórica e iconicamente em espadas de Jedi. Cada personagem, com seu manto-roupão apropriado ao contexto intergaláctico, lutava, não para derrubar a lanterna um do outro, mas para perder a sua própria.

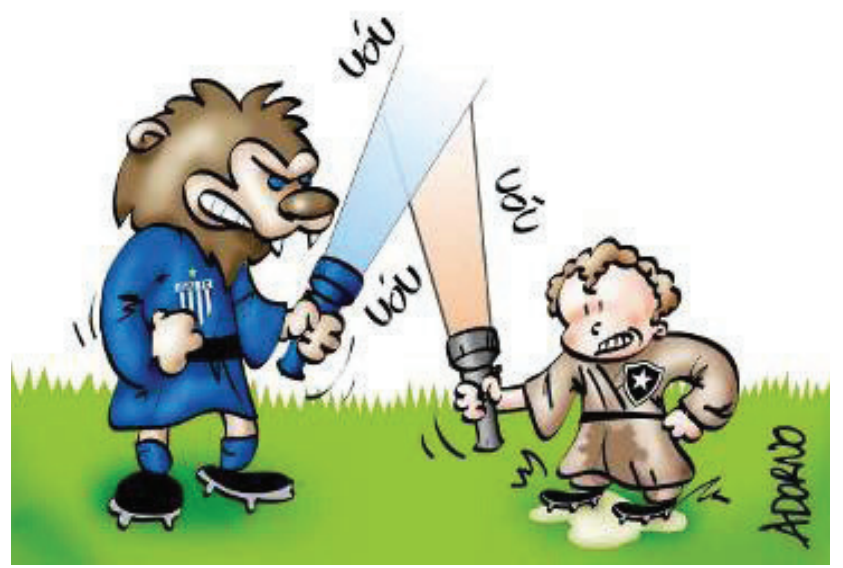

Figura 6. Charge de Adorno.

Fonte: Jornal: "Diário Catarinense" (DC), I I jul. 2009.

Na charge pós-jogo, Zé Dassilva prefere não explicitar o fracasso do Leão na derrota de $2 x \mid$ e, assim, retorna ao tema central da 'lanterna', que já estaria se transformando, hiperbolicamente, numa luz sideral, possível de enxergar não apenas da cabine de um piloto de avião (como anteriormente), mas até fora do planeta, diante de um ônibus espacial. Então, num investimento metonímico, os astronautas identificam a similaridade das cores da terra com a da lanterna do Brasileirão, ambas azuis. 


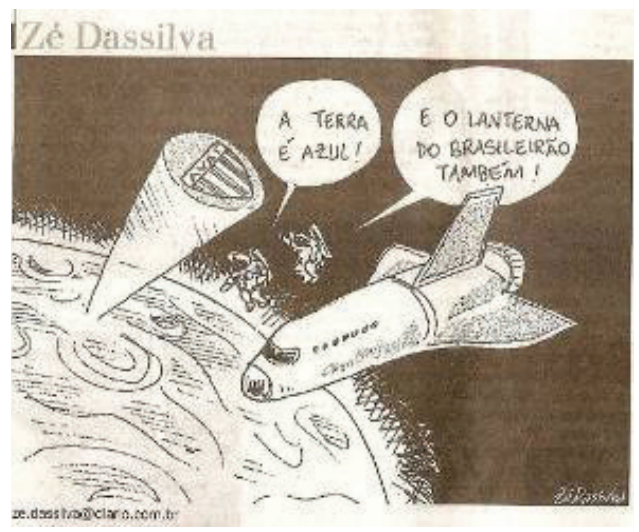

Figura 7. Charge de Zé Dassilva.

Fonte: Jornal: “Diário Catarinense” (DC), 13 jul. 2009.

CONTRASTES E TIPOLOGIA SÍGNICA

Depois de vencer o Vitória por 4x0, na $15^{\mathrm{a}}$ rodada, empatar com 0 Corinthians, 0x0, na I $6^{\mathrm{a}}$, e ainda ganhar do Santo André, I x0, o Leão comemora no alto do penhasco, fazendo embaixadinhas, no traço de Mendes, enquanto observa interrogativo o rival local, despencando da tentativa de acesso à série $\mathrm{A}$.

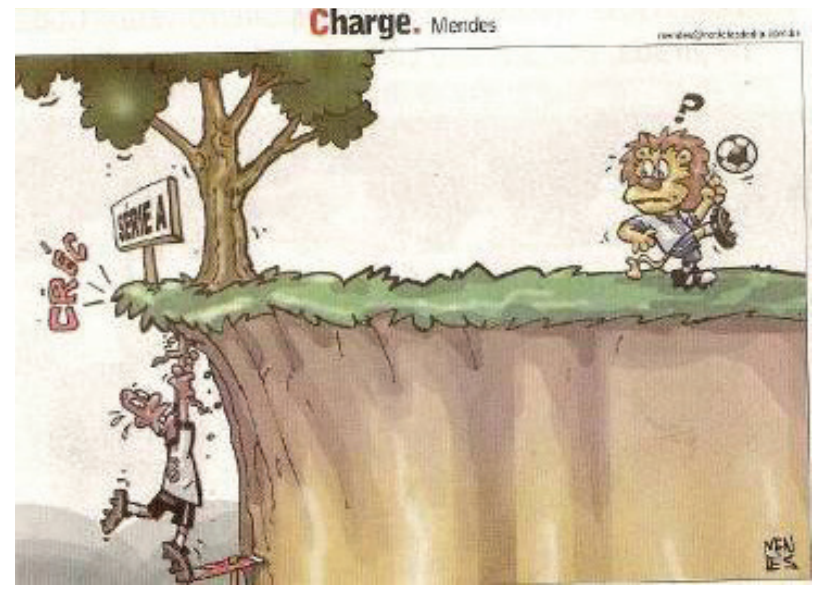

Figura 8. Charge de Mendes.

Fonte: Jornal: "Notícias do Dia" (ND), I0 ago. 2009. 
Mendes estampa essa vantagem do Avaí sobre o Figueirense, sem economizar características positivas ao Leão. É o recurso argumentativo das comparações e contrastes que marca o traço de Mendes. A vantagem de Mendes na produção chargística estudada, em relação aos demais, está no fato de haver nas segundas-feiras um caderno especial de esportes do Notícias do Dia, em que consta uma charge esportiva específica, além da genérica das primeiras páginas diárias.

$\mathrm{Na} 2 \mathrm{I}^{\mathrm{a}}$ rodada, o Avaí realmente deu a sua "volta por cima", vencendo o Flamengo por $3 \times 0$, o que serviu para pautar os três artistas aqui observados. No traço de Adorno, o Leão pisava sobre o Urubu, sinalizando, então, um momento singular para a equipe, que saía da apatia dos empates ou das vitórias sôfregas e começava a distanciar-se da zona de rebaixamento, largando de vez a 'lanterna' metonímica.

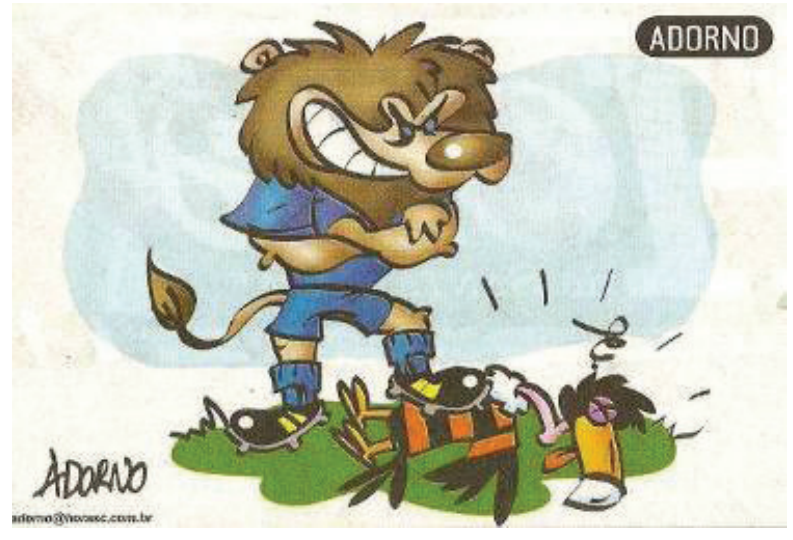

Figura 9. Charge de Adorno.

Fonte: Jornal: "Hora de Santa Catarina" (HSC), 24 ago. 2009.

Zé Dassilva complementa o pós-jogo, mostrando a comemoração do Leão, que levantou um voo muito mais alto do que o Urubu, deixando-o cambaleante, em desvantagem. 


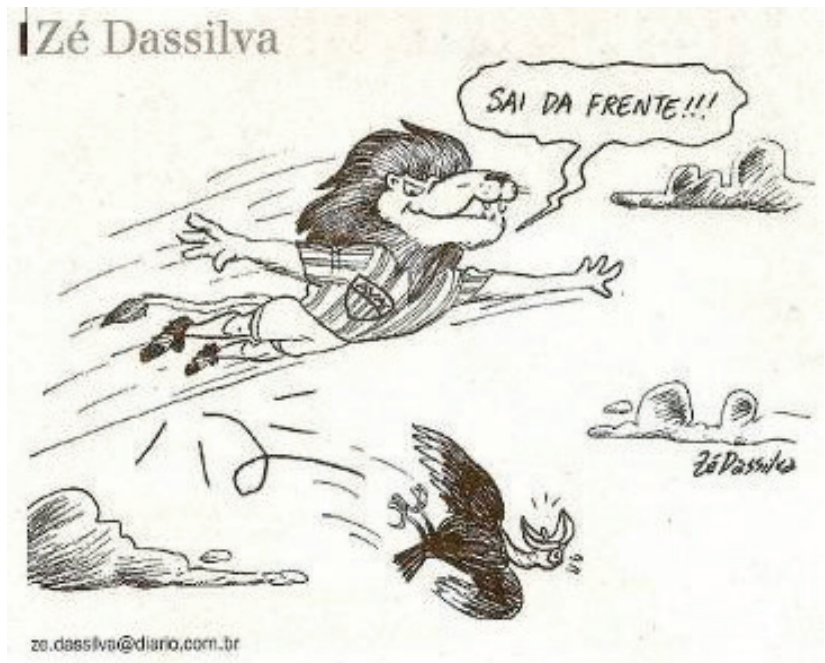

Figura 10. Charge de Zé Dassilva.

Fonte: Jornal: "Diário Catarinense" (DC), 24 ago. 2009.

Ainda numa condição pós-jogo com o Flamengo, Mendes cria uma narrativa em que há mais personagens contracenando com o Leão, ainda que não faça referência explícita ao Flamengo; prefere traçar dois parâmetros distintos em relação à condição do Avaí.

Em primeiro plano, uma associação analógica com a velocidade da Fórmula I, representada metonimicamente pela caricatura do piloto Rubens Barrichello, que raramente é o primeiro colocado, embora fique muitas vezes próximo à pole position. Em segundo plano, há o Negrinho do Figueirense que, indignado com sua atual situação, chuta o próprio veículo que o conduz, sua arma de combate. No meio deles, o Leão destaca que está a caminho do G4 (grupo dos quatro primeiros classificados no campeonato brasileiro, que obtém vaga para a Libertadores de América do ano seguinte). 


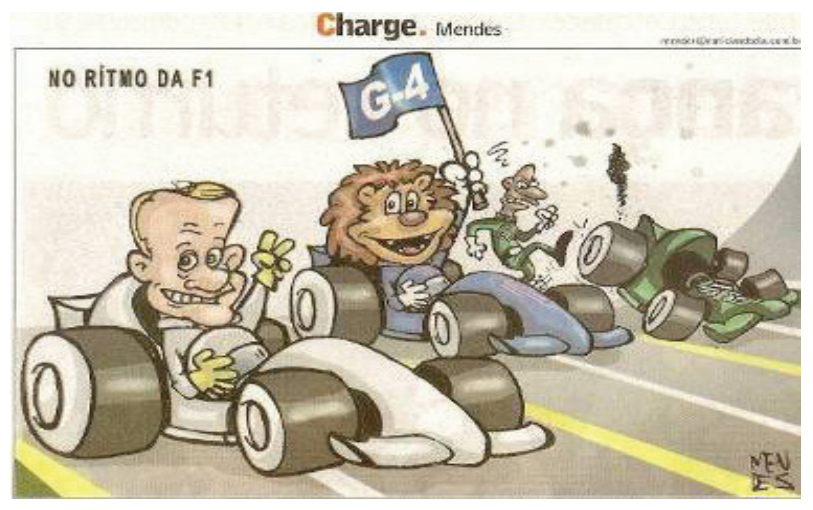

Figura II. Charge de Mendes.

Fonte: Jornal: "Notícias do Dia" (ND), 24 ago. 2009.

Mendes não exalta o Leão, colocando-o numa ação solo, mas insere o personagem numa cena enunciativa, em que é possível dialogar com outros dois assuntos paralelos, também extraídos do mundo esportivo.

O primeiro parâmetro vai mais longe, para ressaltar um elemento como a velocidade/ritmo; e o segundo, mais corriqueiro e, talvez, inevitável, que é a relação contrastiva com o rival local da série $B$.

Somente quando o Leão conseguiu vencer pela segunda vez ao Goiás, na $30^{a}$ rodada, por $2 \times 1$, é que Adorno ressurge na exaltação ao felino, numa charge pós-jogo que difunde a destreza do animal palitando os dentes para tirar os restos de penas verdes do Periquito recém devorado. $\bigcirc$ Periquito se concretiza metonimicamente na narrativa, até porque a legenda acima determina melhor a leitura.

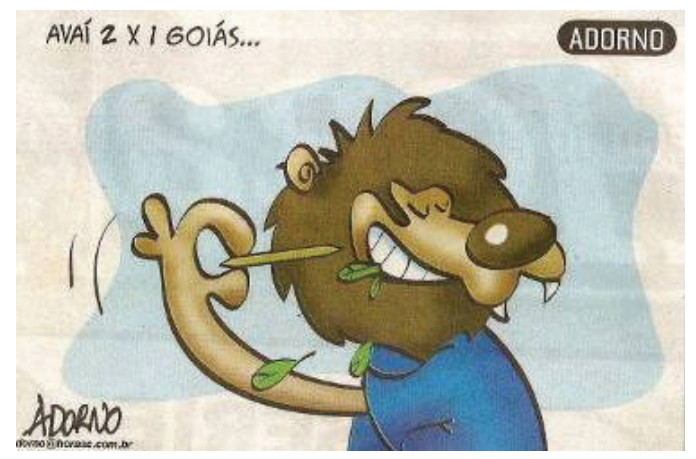

Figura 12. Charge de Adorno.

Fonte: Jornal: "Hora de Santa Catarina" (HSC), 19 out. 2009. 
Até então, já se constata que as marcas de cada chargista estão bem discriminadas, pois há uma frequência de uso de tipos específicos de signos para cada artista, assim como condições enunciativas simples e homogêneas, em Zé Dassilva e Adorno, e complexas e heterogêneas, em Mendes.

Nas últimas rodadas do campeonato, da $36^{\mathrm{a}}$ a $38^{\mathrm{a}}$, os resultados não foram mais chargeados diretamente, mesmo porque esses resultados não foram muito favoráveis para o Leão. Os chargistas investiram, então, em temas paralelos, intertextualizando, ou saíram em busca de novas formas iconográficas, inovando seus traços, construindo signos que são representações diretas de personagens das narrativas factuais e esportivas. Os signos icônicos passam a prevalecer sob o traço dos artistas, deixando para o cenário mais genérico os signos indiciais e simbólicos - as mascotes.

Mendes traz mais uma vez o fenômeno dos parâmetros semânticos, narrando os momentos agonizantes de ambos os signos - Negrinho (do Figueirense) e Leão, com dificuldades de locomoção, por causa de bolas de chumbo presas aos pés, que os impede a chegarem aos seus objetivos. Pode-ser ler a narrativa como um balanço dos dois clubes no Campeonato Brasileiro de 2009: a permanência do Avaí na série A, lamentando, porém, a não conquista de vaga para a Copa Libertadores, e a permanência do Figueirense na série B no ano seguinte.

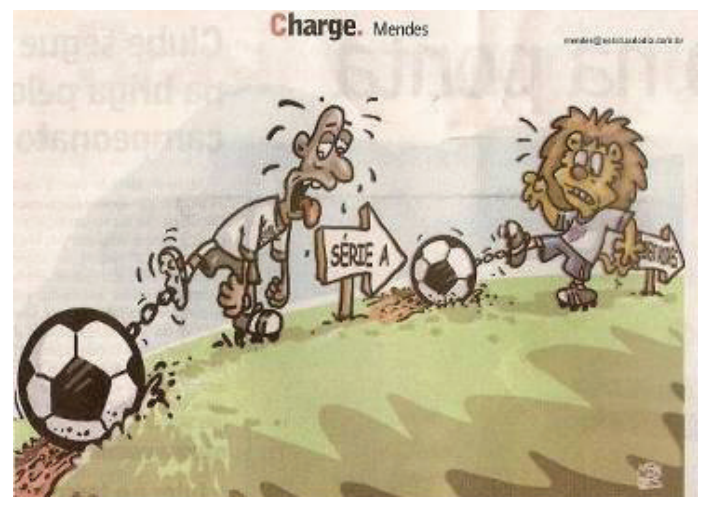

Figura 13. Charge de Mendes.

Fonte: Jornal: "Notícias do Dia" (ND), 23 nov. 2009.

Ainda não tinha acontecido a última rodada, em que o Leão venceria o Náutico por Ix0, mas Zé Dassilva fez a última charge sobre o campeonato brasileiro, após a polêmica da saída antecipada do técnico Silas (Avaí), pondo em cena ambas as mascotes-signos dos times locais, mostrando seu pedido comum de Natal ao Papai Noel. 


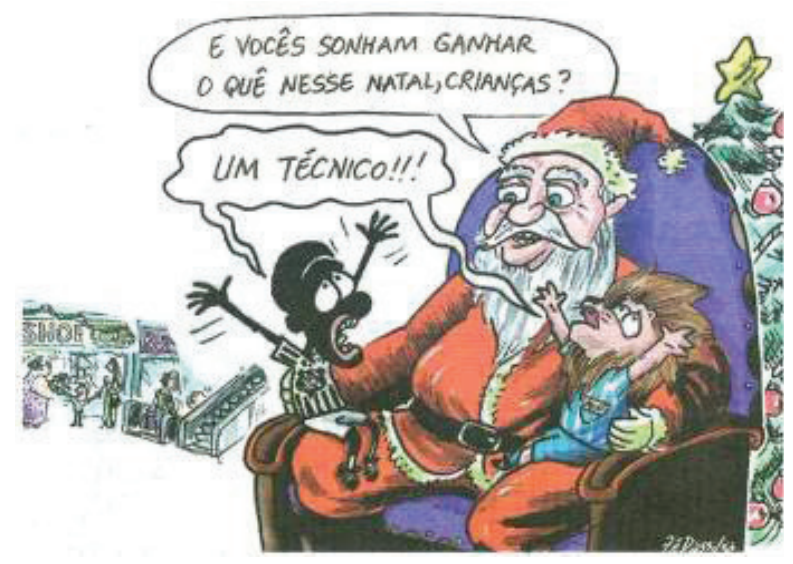

Figura 14. Charge de Zé Dassilva.

Fonte: Jornal: "Diário Catarinense" (DC), 03 dez. 2009.

Previsivelmente, o intertexto aproveitado foi o da celebração da festa de fim de ano, parodiando a situação em que Papais Noéis ficam sentados em shopping centers, ouvindo o pedido das crianças. Eis que surgem, então, versões miniaturas das mascotes - o Negrinho do Figueirense e o Leãozinho do Avaí -, ambos sentados no colo do Papai Noel, pedindo simultaneamente, em tom de jogral exclamativo, um técnico novo.

De forma presumível, o chargeamento do Campeonato Brasileiro 2009 encerra-se depois de uma semiose bastante eclética. Predomina a intertextualidade e o fenômeno paródico, ilustra-se o anseio corriqueiro de todo o fim de competição, em que as peças do jogo já começam a permutarem-se, deixando leitores/ torcedores-modelo atônitos, após um ano de acompanhamento e tietagem das estrelas de seus times.

\section{CONSIDERAÇÕES FINAIS}

Quando se discute o futebol por meio das charges, não se está prolongando a falação esportiva do senso comum. $\bigcirc$ diferencial desta abordagem pode estar neste ponto: quando se fala de futebol por meio da leitura semiótico-discursiva das charges, pretende-se ir além do mero opinar sobre atuação de jogadores e técnicos, encarnando um perfil de comentarista midiático-esportivo. Em função disso, foi imprescindível fundamentar os principais processos de conotação que são o 
metafórico (icônico) e o metonímico (indicial), a partir dos fundamentos da retórica clássica.

Para seguir os caminhos do Leão no Campeonato Brasileiro por meio da leitura das charges, foi preciso adentrar em todo o universo zoossemiótico de representação do futebol, via mascotes, verificando quais eram os animais e símbolos míticos dos demais clubes, personagens que contracenavam com o protagonista Leão. É nas mãos dos chargistas que as mascotes dos clubes de futebol se legitimam e assumem um caráter de existência simbólica efetiva.

No decorrer da análise, além de agrupar as charges temporalmente, quis-se também perceber quais delas eram sumariamente miméticas, em relação ao jogo, e quais delas extrapolavam a lógica dos resultados e estabeleciam outros tipos de relações intertextuais e paródicas.

Observou-se que as charges raramente eram produzidas por consequência de empate nos jogos. Muitas vezes, quando surgiam nessa condição pós-jogo (empate), problematizavam-se outros elementos significativos como a 'lanterna ', ou estabeleciam outras relações de sentidos, como as de contraste entre Avaí e Figueirense, ou a ênfase noticiosa sobre a saída do técnico Silas.

Conforme as charges eram comentadas, se constatavam algumas peculiaridades de cada autor. Viu-se, por exemplo, que as charges de Adorno (HSC) e Zé Dassilva (DC), ambos de jornais do Grupo RBS, tendem a representar obviamente os resultados dos jogos, assumindo um caráter de agenda de partidas, assim como de uma crítica previsível sobre o desempenho do Leão, dispostas em traços mais objetivos, que não exigiam muito esforço interpretativo de seus leitores.

Já as charges de Mendes (ND), da empresa RIC/Record, embora em menor quantidade, mostraram um outro prisma de criatividade. Suas charges geralmente apresentavam-se como narrativas obtusas, inserindo elementos intertextuais e paródicos da factualidade, estabelecendo manobras discursivas mais ousadas, não se constituindo em textos-agenda de partidas. Mendes não se contentava em reproduzir mimeticamente resultados de jogos, preferia estabelecer relações de comparação e contraste, exigindo um maior esforço cognitivo de seu leitor, para a sua interpretação.

É fácil notar que o ND recusa-se à condição de 'notícias populares'; seus textos noticiosos não são pequenos leads, como no HSC; as matérias são assinadas e melhor agrupadas nas páginas fortemente demarcadas como editoriais. Talvez seja por estas razões que o trabalho de Mendes mostra-se mais coerente com o projeto editorial do ND, pois sua charge não é mero penduricalho, tem uma autonomia e espaço próprio, cada quadro é mais do que uma ilustração ou extensão de um texto noticioso já retratado na mesma edição. É uma crônica independente que está atrelada ao projeto editorial do jornal. 
O mesmo fenômeno não se vislumbra nas charges de Adorno, já que está contido num projeto tipicamente de jornal popular (o HSC), pois precisa dialogar homogeneamente com a mesma linguagem, mais apelativa, menos problematizadora. Não se trata aqui de diminuir a produção de um chargista em relação ao outro, mas de constatar que suas diferenças de traço também dependem do tipo de proposta editorial dos veículos em que atuam. As charges de Adorno são meramente ilustrativas, restritas a um único assunto, não estabelecem muitas relações editoriais, sãopertinentes ao tipo do jornal.

Já o trabalho de Zé Dassilva, por fazer parte da página 3 do DC, não extrapola os limites de Adorno, mantém-se num diálogo com o leitor, no mesmo nível. Pensa-se que o artista poderia extravasar ideologicamente, até pelo fato de ter um acúmulo maior de experiência, com atuação mais eclética em outras linguagens, como a de roteiro e audiovisual, no eixo Rio-São Paulo. Talvez por uma questão de contingência e comodidade, as charges de Zé Dassilva cumprem um papel tímido para um cronista iconográfico de um jornal de referência como o DC.

Só mesmo as charges, enquanto narrativas do gênero jornalístico opinativo, é que dão longevidade às representações simbólicas dos times de futebol, são como suportes técnico-estéticos que permitem maior visibilidade dos clubes aos leitores-torcedores, mantendo ou ressignificando as formas significantes fundadoras, sintetizadas em figuras de mascotes.

Como se aceleram cada vez mais as trocas de atletas e técnicos das equipes de futebol, num verdadeiro exercício de interesses mercadológicos, só resta ao torcedor vibrar pelo seu time a partir de sua insígnia, da cadeia de signos pela qual o clube se institui simbolicamente.

leitor-modelo do jornalismo esportivo sobre futebol não torce pelos jogadores, nem pelos técnicos. $\bigcirc$ que o faz manter a sua paixão pelo clube é o cardápio simbólico que lhe é oferecido, do qual as mascotes-signos fazem parte. As charges, portanto, é que mantêm viva a imagem do clube ao torcedor, fazendo-o crer que aquela equipe, condensada numa única figura simbólica, está em constante atuação, protagonizando uma narrativa interminável, na qual tenta permanecer na batalha, dia-a-dia, para a conquista de mais pontos e novos títulos.

Trajectory of Avaí Futebol Clube in the Brazilian Championship 2009: a study of speech-semiotic charges on daily news

ABSTRACT: This work provides to physical education teachers a theoretical support on critical-discursive-semiotic analysis of newspaper cartoons about soccer in Florianópolis. This is a reading on the performance of Avaí Futebol Clube in the Brazilian Championship in 2009, from cartoons produced from May to December of that year by Zé Dassilva (Diário 
Catarinense), Mendes (Notícias do Dia) and Adorno (Hora de Santa Catarina). The analytical path takes into account a peculiar choice of cartoons arranged chronologically, which contrast by highlighting some phenomena and fundamental elements of the semiosic processes and narrative speeches of Lion's performance over the League, like metaphorization, metonymy and intertextuality.

KEY WORDS: Discursive-semiotic analysis; newspaper cartoons; Brazilian championship soccer; Avaí Futebol Clube.

\section{Los destinos del Avaí Futebol Clube en el Campeonato Brasileño/2009: lectura de caricaturas periódisticas}

RESUMEN: Este trabajo proporciona a profesores de educación física un respaldo teóricocrítico sobre el análisis semiótico-discursivo de las caricaturas de fútbol en los periódicos de la Grande Florianópolis. Se trata de una lectura del rendimiento del Avaí Futebol Clube en el Campeonato Brasilero en 2009, a partir de las caricaturas producidas de mayo a diciembre de ese año por Zé Dassilva (Diario de Santa Catarina), Mendes (Noticias do Dia) y Adorno (Hora de Santa Catarina). El camino analítico tiene en cuenta una peculiar elección de las caricaturas, dispuestas cronológicamente, que se destacan por evidenciar algunos fenómenos y elementos constituyentes de los procesos semióticos y discursivos de las narrativas sobre el rendimiento del León a lo largo del campeonato, como metáfora y metonimia.

PALABRAS CLAVES: Análisis semiótico-discursivo; caricaturas periodísticas; campeonato brasilero de fútbol; Avaí Futebol Clube.

\section{REFERÊNCIAS}

ALMEIDA, L. M.; OLIVEIRA, N. A. A. Gêneros jornalísticos opinativos e de humor: caricaturas e charges. Janus, Lorena, ano 3, n. 4, 2006.

ALVES, R. J. A.; SANTOS, G. F. A excitação no discurso televisivo dos Jogos Pan-Americanos do Brasil: um estudo da transmissão da Rede Globo de Televisão. Movimento, Porto Alegre, v. 16, n. I, p. 227-244, jan./mar. 2010.

AMARAL, L. Técnica de jornal e periódico. Rio de Janeiro: Tempo Brasileiro, 1982.

BARONAS, R. L.; AGUIAR, G. F. Do acontecimento histórico ao acontecimento discursivo: o político na charge. Bakhtiniana, São Paulo, v. I, n. 2, p. 165-182, 2009. Disponível em: <http://revistas.pucsp.br/index.php/bakhtiniana/article/download/30 17/1948>. Acesso em: 18 nov. 2009

BITTENCOURT, F. G. et al. Processos de produção do discurso midiático-esportivo: observando a cobertura jornalística dos Jogos Abertos de Santa Catarina/2007. Caderno de Educação Física (UNIOESTE), Marechal Cândido Rondon, v. 8, p. 09-19, 2009. 
CAMARAJUNIOR., J. M. Dicionário de lingüística e gramática. 16. ed. Petrópolis: Vozes, 1986.

CAMARGO, V. R. T. Copa do Mundo de futebol: análise da construção jornalística da mensagem esportiva. Revista Digital, Buenos Aires, ano 5, n. 20, 2000. Disponível em: www. efdeportes.com. Acesso em: 18 nov. 2009.

CAVALCANTI, M. C. C. Multimodalidade e argumentação na charge. 2008. I I 2 f. Dissertação (Mestrado em Linguística) - Programa de Pós-Graduação em Letras, Universidade Federal de Pernambuco, Recife, 2008.

ERBOLATO, M. Jornalismo especializado: emissão de textos no jornalismo impresso. São Paulo: Ática, 1981.

FREITAS, G. S.; RIGO, L. C. Discursos de uma derrota: um estudo da produção discursiva sobre a eliminação da seleção brasileira na copa do mundo de 2006. Revista Brasileira de Ciências do Esporte, Campinas, v. 30, n. 3, p. I | | - 125, maio 2009.

KOCH, I. V. O texto e a construção de sentidos. 3. ed. São Paulo: Contexto, 2000.

MAGALHÃES, A. P. Sentido, história e memória em charges eletrônicas sobre o Governo Lula: os domínios do interdiscurso. 2006. 247 f. Dissertação (Mestrado em Letras) - Programa de Pós-Graduação em Letras, Universidade Estadual de Maringá, Maringá, 2006.

MARCUSCHI, L. A. Gêneros textuais: definição e funcionalidade. In: DIONÍSIO, A. et al. Gêneros textuais e ensino. Rio de Janeiro: Lucerna, 2003.

MARQUES, D. R. O humor na capa: uma análise semiótica do discurso. Cadernos de Letras da UFF: Dossiê: Literatura e Humor, Niterói, n. 37, p. 61-68, 2ºm. 2008.

MELO, J. M. de. Jornalismo opinativo: gêneros opinativos no jornalismo brasileiro. São Paulo: Mantiqueira, 2003.

MESSA, F. C. Construindo o complexo de Adônis - um estudo sobre o discurso editorial da revista Men's Health. In: CONGRESSO BRASILEIRO DE CIÊNCIAS DO ESPORTE, I6., Salvador, 2009. Anais... Salvador: CBCE, 20 a 25 de setembro de 2009. Disponível em: <http://www.rbceonline.org.br/congressos/index.php/CONBRACE/XVI>. Acesso em: 18 nov. 2009.

MESSA, F. C. Os destinos do Leão. Um estudo semiótico-discursivo das charges jornalísticas sobre o Avaí Futebol Clube no campeonato brasileiro/2009. 20 I0. I89 f. Dissertação (Mestrado em Educação Física) - Programa de Pós-Graduação em Educação Física, Universidade Federal de Santa Catarina, Florianópolis, 2010.

MEZZAROBA, C.; PIRES, G. L. O agendamento midiático-esportivo: considerações a partir dos Jogos Pan-americanos Rio/2007. Logos (UERJ - Online), Rio de Janeiro, v. 33, p. I24136, 20 10. Disponível em: <http://www.logos.uerj.br/PDFS/33/I0_logos33_mezzaroba_ pires_agendamento.pdf>. Acesso em: 18 nov. 2009 
MOURA, A. C. A interdiscursividade na charge - pontos de contato entre o discurso político e o esportivo. In: CONGRESSO DE PESQUISA E INOVAÇÃO DA REDE NORTE NORDESTE DE EDUCAÇÃO TECNOLÓGICA, 5. Anais... Disponível em http://connepi.ifal.edu.br/ocs/ index.php/connepi/CONNEPI20 I0>. Acesso em: 18 nov. 2009.

NOGUEIRA, A. A. A charge: função social e paradigma cultural. intercom. In: CONGRESSO BRASILEIRO DE CIÊNCIAS DA COMUNICAÇÃO, 26., Belo Horizonte, 2003. Anais... Belo Horizonte: Sociedade Brasileira de Estudos Interdisciplinares da Comunicação. Disponível em: http://pt.scribd.com/doc/54569199/Charge-Como-Funcao-Social-e-Cultural. Acesso em: I 8 nov. 2009.

PIRES, G. L. (Org.). "Observando" o Pan Rio/2007 na mídia. Florianópolis: Tribo da llha, 2009. PLAZA, J. Tradução intersemiótica. São Paulo: Perspectiva, 200 I.

PROPP, V. Comicidade e riso. São Paulo: Ática, 1992.RABAÇA, C. A.; BARBOSA, G. Dicionário de comunicação. São Paulo: Codecri, 1978.

SANFELICE, G. R. Campo midiático e campo esportivo: suas relações e construções simbólicas. Revista Brasileira de Ciências do Esporte, Campinas, v. 31 , n. 2, p. I37-I53, jan. 2010. TREVISAN, E. Leitura: coerência e conhecimento prévio. Santa Maria: Ed. da UFSM, 1992. JORNAIS UTILIZADOS NA ANÁLISE

DIÁRIO CATARINENSE (DC), ano 2009. Edições: 5/6, II/7, 13/7, 24/8, 3/12.

HORA DE SANTA CATARINA (HSC), ano 2009. Edições: 30/5, I/6, 18/6, 1 I/7, 24/8, 19/10. NOTíCIAS DO DIA (ND), ano 2009. Edições: I0/8, 24/8, 23/II.

Recebido: 16 maio 2010 Aprovado: 10 fev. 2011

Endereço para correspondência: Fábio de Carvalho Messa Av. Atlantica, 892/I00 I Caiobá - Matinhos - PR - 83260-000 